Available online at GSC Online Press Directory

GSC Biological and Pharmaceutical Sciences

e-ISSN: 2581-3250, CODEN (USA): GBPSC2

Journal homepage: https://www.gsconlinepress.com/journals/gscbps

(REVIEW ARTICLE)

\title{
Vector-mediated cancer gene therapy: A review
}

\author{
Manisha. B. Shinde *, Dr. Archana D. Kajale, Dr. Madhuri A. Channawar and Dr. Shilpa R. Gawande
}

Department of Pharmaceutical P. Wadhwani College of pharmacy Yavatmal. (M.S). 445001, India.

Publication history: Received on 10 November 2020; revised on 18 November 2020; accepted on 20 November 2020

Article DOI: https://doi.org/10.30574/gscbps.2020.13.2.0368

\begin{abstract}
Gene therapy is the transfer of genetic material to cure a disease or at least to improve the clinical status of a patient. One of the basic concepts of gene therapy is to transform viruses into genetic shuttles, which will deliver the gene of interest into the target cells. Safe methods have been devised to do this, using several viral and non-viral vectors. Two main approaches emerged: in vivo modification and ex vivo modification. Retrovirus, adenovirus, adenoassociated virus are suitable for gene therapeutic approaches which are based on permanent expression of the therapeutic gene. Nonviral vectors are far less efficient than viral vectors, but they have advantages due to their low immunogenicity and their large capacity for therapeutic DNA. The most commonly used DNA virus vectors are based on adenoviruses and adenoassociated viruses. An example of gene-knockout mediated gene therapy is the knockout of the human CCR5 gene in Tcells in order to control HIV infection. To improve the function of non-viral vectors, the addition of viral functions such as receptor mediated uptake and nuclear translocation of DNA may finally lead to the development of an artificial virus. Gene transfer protocols have been approved for human use in inherited diseases, cancers and acquired disorders. Although the available vector systems are able to deliver genes in vivo into cells, the ideal delivery vehicle has not been found. Thus, the present viral vectors should be used only with great caution in human beings and further progress in vector development is necessary.
\end{abstract}

Keywords: Gene therapy; Lentiviruses; Transducer; RNA vector; Adeno-associated viruses; Viral vector; Immunogenicity

\section{Introduction}

Gene therapy typically involves the insertion of a functioning gene into cells to correct a cellular dysfunction or to provide a new cellular function [1]. For example, diseases such as cystic fibrosis, combined immunodeficiency syndromes, muscular dystrophy, haemophilia, and many cancers result from the presence of defective genes. Gene therapy can be used to correct or replace the defective genes responsible. Gene therapy has been especially successful in the treatment of combined immunodeficiency syndromes, showing lasting and remarkable therapeutic benefit. [2-3]

Gene therapy is a technique for correcting defective genes responsible for disease development. Researchers may use one of several approaches for correcting faulty genes: A normal gene may be inserted into a nonspecific location within the genome to replace a non-functional gene. This approach is most common. An abnormal gene could be swapped for a normal gene through homologous recombination. The abnormal gene could be repaired through selective reverse mutation, which returns the gene to its normal function. Gene therapy is the insertion, alteration, or removal of genes within an individual's cells and biological tissues to treat diseases. It is a technique for correcting defective genes that are responsible for disease development. A second class of gene therapy involves altering the expression of an endogenous gene in a cell. This can be achieved by transferring a relatively short piece of genetic material ( 20 to $50 \mathrm{bp}$ )

\footnotetext{
* Corresponding author: Manisha. B. Shinde

Department of Pharmaceutical P. Wadhwani college of pharmacy Yavatmal. (M.S). 445001, India.
}

Copyright (c) 2020 Author(s) retain the copyright of this article. This article is published under the terms of the Creative Commons Attribution Liscense 4.0. 
that is complementary to the mRNA. This transfer would affect gene expression by any of a variety of mechanisms through blocking translational initiation, mRNA processing, or leading to destruction of the mRNA. Alternatively, a gene that encodes antisense RNA that is complementary to a cellular RNA can function in a similar fashion.

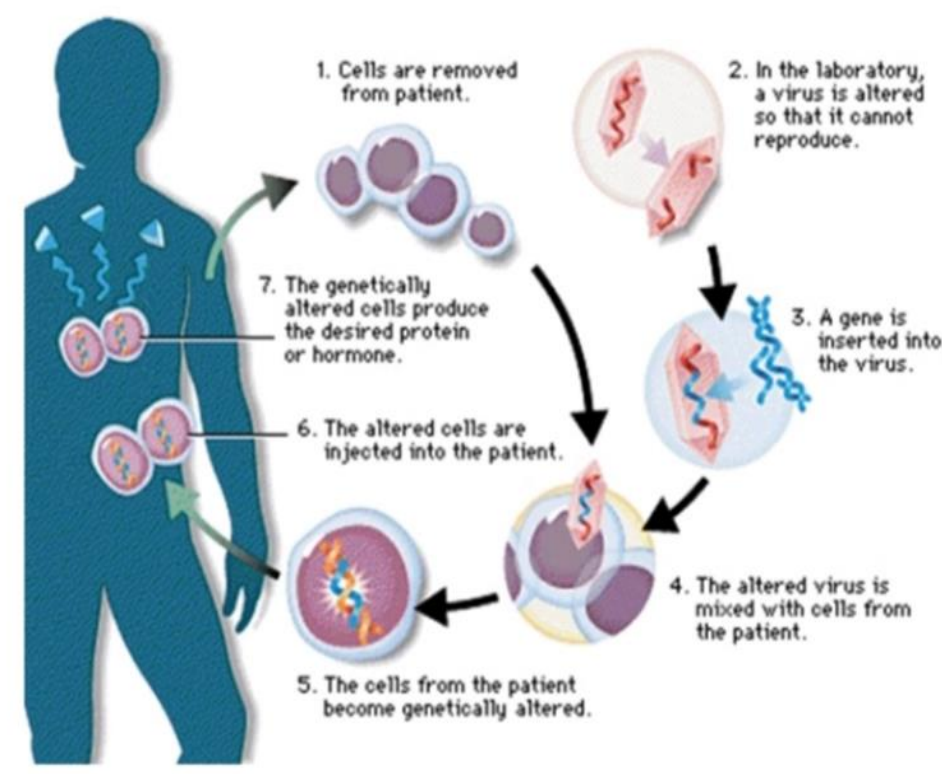

Figure 1 Flow chart shows gene therapy

\section{Applications of gene therapy}

Gene therapy is likely to have the greatest success with diseases that are cause by single gene defects. By the end of 1993, gene therapy had been approved for use on such diseases as severe combined immune deficiency, familial hypercholesterolemia, cystic fibrosis, and Gaucher's disease. Most protocols to date are aimed toward the treatment of cancer; a few are also targeted toward AIDS. Numerous disorders are discussed as candidates for gene therapy: Parkinson's and Alzheimer's diseases, arthritis, and heart disease. The Human Genome Project, an ongoing effort to identify the location of all the genes in the human genome, continues to identify genetic diseases [4, 5]. Eve Nichols describes the criteria for selection of disease for human gene therapy [6]:

- The disease is an incurable, life-threatening disease;

- Organ, tissue and cell types affected by the disease have been identified.

- The normal counterpart of the defective gene has been isolated and cloned.

- The normal gene can be introduced into a substantial sub fraction of the cells from the affected tissue; or that introduction of the gene into the available target tissue, such as bone marrow, will somehow alter the disease process in the tissue affected by the disease.

- The gene can be expressed adequately (it will direct the production of enough normal protein to make a difference).

- Techniques are available to verify the safety of the procedure.

\section{Principles of gene therapy: selection of a gene, a vector and a management strategy}

\subsection{Selection of the gene}

\subsubsection{Mutant gene correction}

The principles of gene selection strategies are illustrated in Figure 2. In the case of inherited monogenic diseases, the aim of gene therapy is to transfer and express the defective gene. The situation is more complex in cancer gene therapy because cancer most often results from sequential genetic and epigenetic alterations, affecting oncogenes, tumoursuppressor genes and microRNAs. One gene therapy approach is, thus, to restore tumour-suppressor gene expression or to inhibit oncogene expression. About 11\% of transferred genes in gene therapy clinical trials are tumour-suppressor 
genes and many trials have been performed in cancer gene therapy using the p53 gene, mostly including patients with lung or head and neck cancers.

\subsubsection{Suicide genes}

The aim of suicide gene therapy is to enable, selectively, the transfected cell to transform a prodrug into a toxic metabolite, resulting in cell death. The most widely described suicide gene is the herpes simplex virus thymidine kinase (HSV-tk) gene. HSV-tk can phosphorylate ganciclovir, which is a poor substrate for mammalian thymidine kinases. Ganciclovir can therefore be transformed into ganciclovir triphosphate, which is cytotoxic to the transfected cell, resulting in cell death. [7] This cell death can also affect neighbouring cells that do not express HSV-tk. This phenomenon is called a local bystander effect, as opposed to a bystander effect that can be observed in distant, nontransduced tumour sites. [8] This distant bystander effect involves the immune system.

\subsubsection{Immunotherapy}

Cancer immunotherapy has been developed to stimulate immune response against tumour cells. Gene therapy can be used to transfer genes into tumour cells to render them more highly immunogenic. Gene transfer of tumour-specific antigens, co-stimulatory molecules and/or inflammatory cytokines has been assessed. Tumour-associated antigens can be recognized by $\mathrm{T}$ lymphocytes. These antigens can be derived from oncogenic viruses (Epstein-Barr virus, human papillomavirus) or can be self-antigens. These self-antigens can be overexpressed antigens or antigens that are altered by virtue of a gene mutation or a post-translational modification. They can also be onco-foetal antigens, such as $5 \mathrm{~T} 4$ antigen and carcinoembryonic antigen (CEA). [9] Immunization against a specific antigen can induce cellular and/or humoral immune responses. T-cell activation requires not only the interaction between major histocompatibility molecules bearing a specific peptide and the T-cell receptor, but also non-antigen-specific co-stimulatory activation by interaction of molecules expressed on the T-cell and the antigen presenting cells (such as interactions between CD28 and CTLA-4 expressed on the T-cell and B7 expressed on the antigen presenting cells). Finally, vectors encoding inflammatory molecule genes [such as interleukin-2, interleukin-12, TNF-a, interferon-c, granulocyte macrophage colony-stimulating factor (GM-CSF)] have been engineered. In terms of the site of gene transfer, immunization can be carried out in situ in the tumour or at a distant site.

\subsubsection{RNA interference}

RNA interference is a promising new therapeutic approach for many diseases, including.

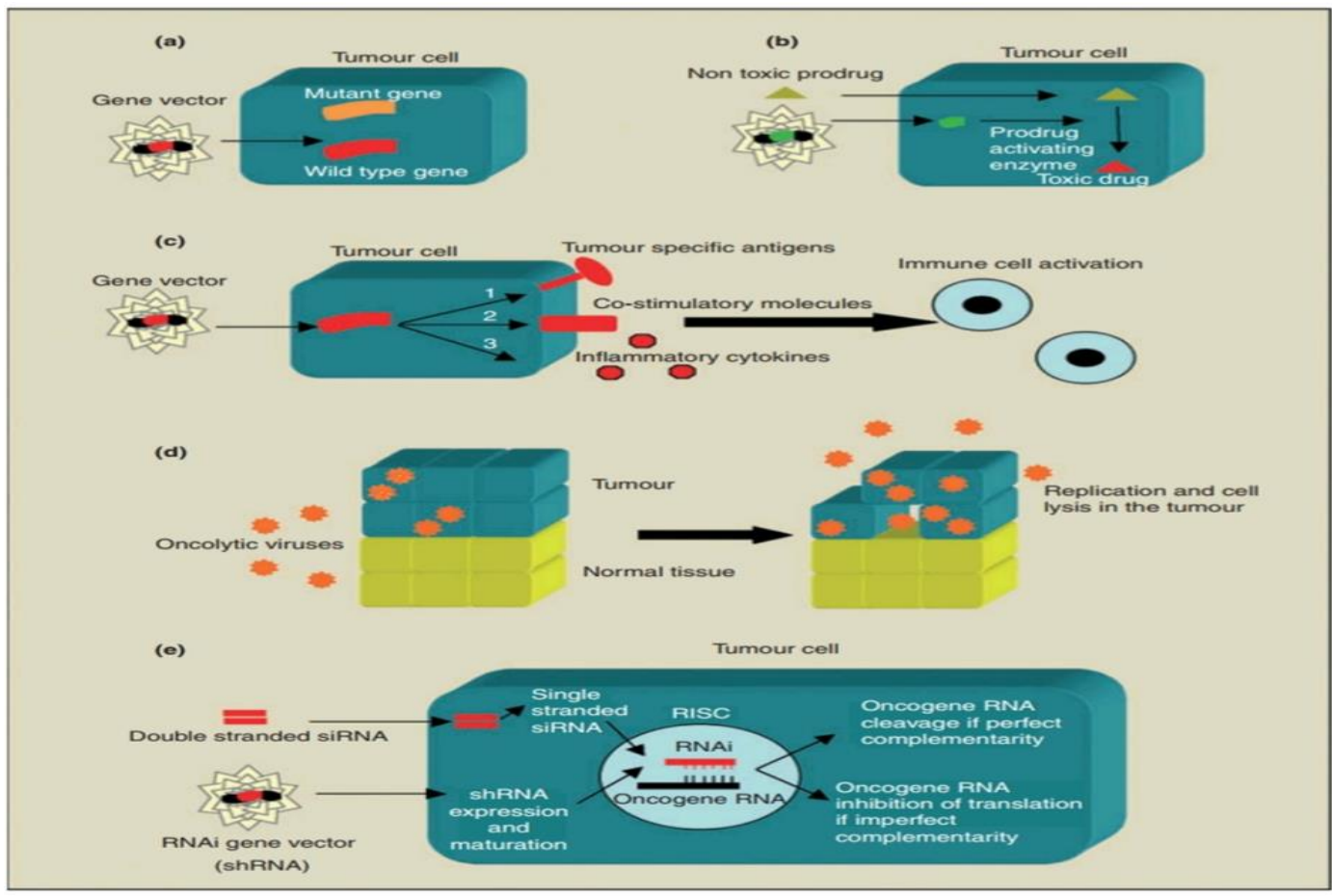

Figure 2 Principles of gene therapy 
Gene re-expression. The vector carries a wild-type version of a mutant gene into the tumour. (b) Suicide therapy. A combination of the systemic administration of a nontoxic prodrug and the tumour-specific delivery of the prodrugactivating enzyme gene. (c) Immune therapy. The vector carries a gene encoding a specific immunogenic tumour antigen (1), a co-stimulatory signalling molecule (2) or an inflammatory cytokine (3), leading to immune stimulation. (d) Oncolytic viruses. Oncolytic viruses specifically replicate in, and kill, tumour cells. (e) Therapeutic RNA interference. The RNAi (siRNA) or the RNAi gene (shRNA) is delivered into the cell. After maturation and incorporation in the RNAinduced silencing complex (RISC), RNAi can bind an oncogene RNA, leading to oncogene repression and cell death.

\subsection{Vectors}

Facilitating the transfer of genetic information into a cell are vehicles simply called as vectors. Vectors can be divided into viral and nonviral delivery systems. The most commonly used viral vectors are derived from retrovirus, adenovirus and adeno-associated virus (AAV). Other viral vectors that have been less extensively used are derived from herpes simplex virus 1 (HSV-1), vaccinia virus, or baculovirus. Nonviral vectors can be either plasmid deoxyribonucleic acid (DNA), which is a circle of double-stranded DNA that replicates in bacteria or chemically synthesized compounds that are or resemble oligodeoxynucleotides. [10] Major considerations in determining the optimal vector and delivery system are (a) the target cells and its characteristics, that is, the ability to be virally transduced ex vivo and reinfused to the patient, (b) the longevity of expression required and (c) the size of the genetic material to be transferred. Characteristics of viruses that have been used to generate viral vectors is shown in Table-1.

Table 1 Characteristics of Viruses that have been used to Generate Viral Vectors.

\begin{tabular}{|c|c|c|c|c|}
\hline Virus & Size and type of genome & $\begin{array}{l}\text { Viral } \\
\text { proteins }\end{array}$ & $\begin{array}{l}\text { Physical } \\
\text { properties }\end{array}$ & Disease in Animal \\
\hline Retrovirus & $\begin{array}{l}7-10 \mathrm{~kb} \text { of } \quad \text { single } \\
\text { stranded RNA }\end{array}$ & Gaga, Pol, Env & $\begin{array}{l}\text { 100nm } \\
\text { diameter; } \\
\text { enveloped }\end{array}$ & $\begin{array}{l}\text { Rapid or slow induction of } \\
\text { tumors; } \\
\text { immunodeficiency } \\
\text { (AIDS }\end{array}$ \\
\hline Adenovirus & $\begin{array}{l}\text { 36kb double stranded } \\
\text { linear DNA }\end{array}$ & $\begin{array}{l}\text { Over } \quad 25 \\
\text { proteins }\end{array}$ & $\begin{array}{l}\text { 70-100nm in } \\
\text { diameter; } \\
\text { nonenveloped }\end{array}$ & $\begin{array}{l}\text { Cold; } \\
\text { gastroenteritis }\end{array}$ \\
\hline $\begin{array}{l}\text { Adenovirus } \\
\text { associated virus }\end{array}$ & $\begin{array}{l}\text { 4-7 } \mathrm{kb} \text { single stranded } \\
\text { linear DNA }\end{array}$ & Rep and Cap & $\begin{array}{l}\text { 18-26nm in } \\
\text { diameter; } \\
\text { nonenveloped }\end{array}$ & No known disease \\
\hline $\begin{array}{l}\text { Herpes simplex } \\
1(\text { HSV1) }\end{array}$ & $\begin{array}{l}152 \mathrm{~kb} \text { of double } \\
\text { stranded linear DNA }\end{array}$ & $\begin{array}{l}\text { Over } \quad 81 \\
\text { proteins }\end{array}$ & $\begin{array}{l}\text { 110nm in } \\
\text { diameter }\end{array}$ & $\begin{array}{l}\text { Mouth ulcers; genital warts; } \\
\text { encephalitis }\end{array}$ \\
\hline Vaccinia virus & $\begin{array}{l}190 \mathrm{~kb} \text { of double } \\
\text { stranded linear DNA }\end{array}$ & $\begin{array}{l}\text { Over } \quad 198 \\
\text { open reading } \\
\text { frames virus }\end{array}$ & $\begin{array}{l}350 \text { by } 270 \mathrm{~nm} \\
\text { rectangles; } \\
\text { enveloped }\end{array}$ & $\begin{array}{l}\text { Attenuated virus that was used to } \\
\text { vaccinate against smallpox }\end{array}$ \\
\hline Baculovirus & $\begin{array}{l}130 \mathrm{~kb} \text { of double } \\
\text { stranded circular DNA }\end{array}$ & $\begin{array}{l}\text { Over } \quad 60 \\
\text { proteins }\end{array}$ & $\begin{array}{l}270 \text { by } 45 \mathrm{~nm} \\
\text { rectangles; } \\
\text { enveloped }\end{array}$ & $\begin{array}{l}\text { None in mammals; insect } \\
\text { pathogen }\end{array}$ \\
\hline
\end{tabular}

Gag is a polyprotein and is an acronym for group antigen (ag), b- Pol is reverse transcriptase, c- Env is envelop protein, d- Rep is replication viral gene, e- Cap is capsid viral gene.

\subsection{Vectors in gene therapy}

Some of the different types used as gene therapy vectors:

\subsubsection{Retrovirus}

A class of viruses that can create double-stranded DNA copies of their RNA genomes. These copies of its genome can be integrated into the chromosomes of host cells. Human immunodeficiency virus (HIV) is a retrovirus. Eg:- One of the problems of gene therapy using retroviruses is that the integrase enzyme can insert the genetic material of the virus 
into any arbitrary position in the genome of the host; it randomly inserts the genetic material into a chromosome. If genetic material happens to be inserted in the middle of one of the original genes of the host cell, this gene will be disrupted (insertional mutagenesis). If the gene happens to be one regulating cell division, uncontrolled cell division (i.e., cancer) can occur. This problem has recently begun to be addressed by utilizing zinc finger nucleases [11] or by including certain sequences such as the beta-globin locus control region to direct the site of integration to specific chromosomal sites.

\subsubsection{Adenoviruses}

A class of viruses with double-stranded DNA genomes that cause respiratory, intestinal, and eye infections in humans. The virus that causes the common cold is an adenovirus.

\subsubsection{Adeno}

Associated viruses- A class of small, single-stranded DNA viruses that can insert their genetic material at a specific site on chromosome. [12]

\subsubsection{Cis and trans-acting elements}

Replication-defective vectors always contain a "transfer construct". The transfer construct carries the gene to be transduced or "transgene". The transfer construct also carries the sequences which are necessary for the general functioning of the viral genome: packaging sequence, repeats for replication and, when needed, priming of reverse transcription. These are denominated cis-acting elements, because they need to be on the same piece of DNA as the viral genome and the gene of interest. [13]

\subsubsection{Herpes simplex viruses}

A class of double-stranded DNA viruses that infect a particular cell type, neurons. Herpes simplex virus type 1 is a common human pathogen that causes cold sores. [14]

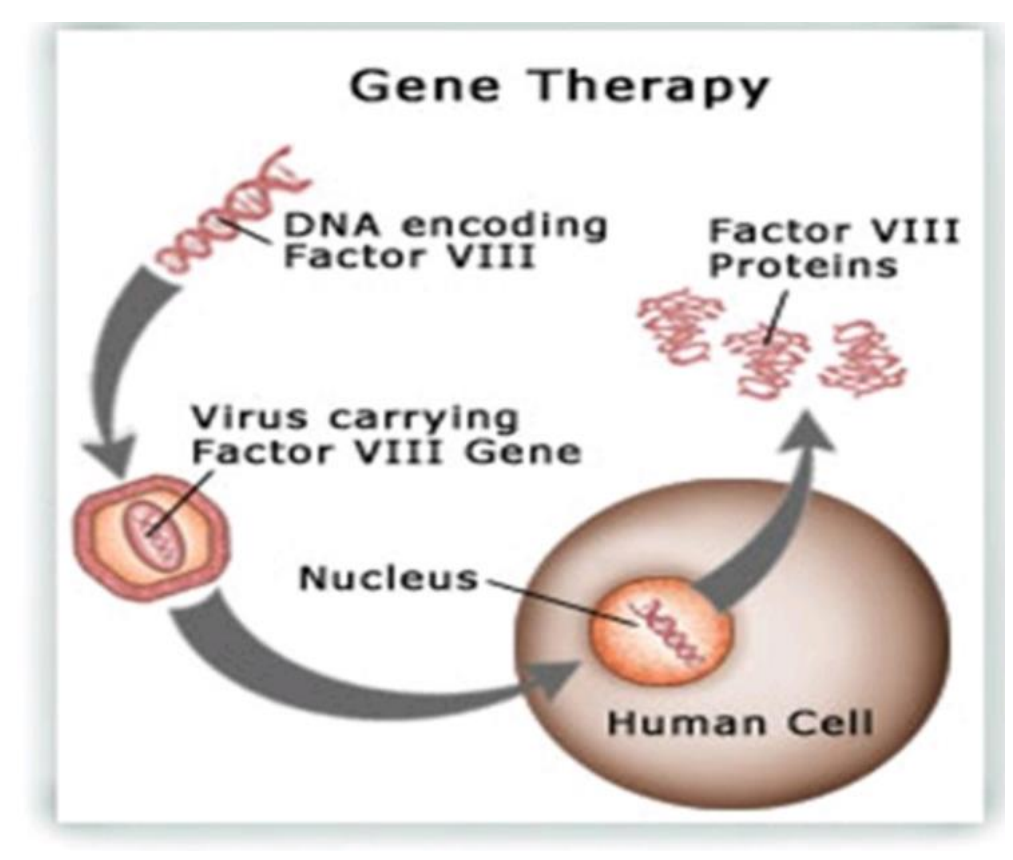

Figure 3 viral method of gene therapy

\subsection{Non viral method}

In comparison with virus-derived vectors, non-viral vectors have several advantages, such as the safety of administration without immunogenicity, almost unlimited transgene size and the possibility of repeated administration. [15] Non-viral gene delivery systems generally consist of three categories: (a) naked DNA delivery, (b) lipid-based and (c) polymer-based delivery. [16] 


\subsection{Naked plasmid DNA}

Attractive The simplest technique of non-viral gene transfer is the use of so called naked DNA. A series of approaches for naked plasmid DNA based gene delivery strategies have been reported inrecent years like, naked plasmid DNA transfer method wherein a cytotoxic T-lymphocyte antigen 4- immunoglobulin (CTLA4-Ig) gene was delivered using a naked plasmid DNA.[17] Naked DNA was used for antiangiogenic therapy where the fetals liver kinase-1 gene was delivered.[18] One more interesting area that is the use of naked plasmid DNA gene delivery as electro gene therapy which is done after injection of naked plasmid DNA and delivery of electric pulses directly to the tissue the expression of gene of interest can be obtained[19], because of its inherent simplicity naked DNA is an non-viral vector and moreover its ease of production in bacteria and manipulation using standard recombinant DNA techniques substantiates its use as non-viral gene delivery system. The other important advantage in using naked DNA gene delivery system is its ability to show very little dissemination and transfection at distant sites following delivery and also can be administered several times as it does not show any antibody response against itself.[20]

Liposomes for Drug Delivery

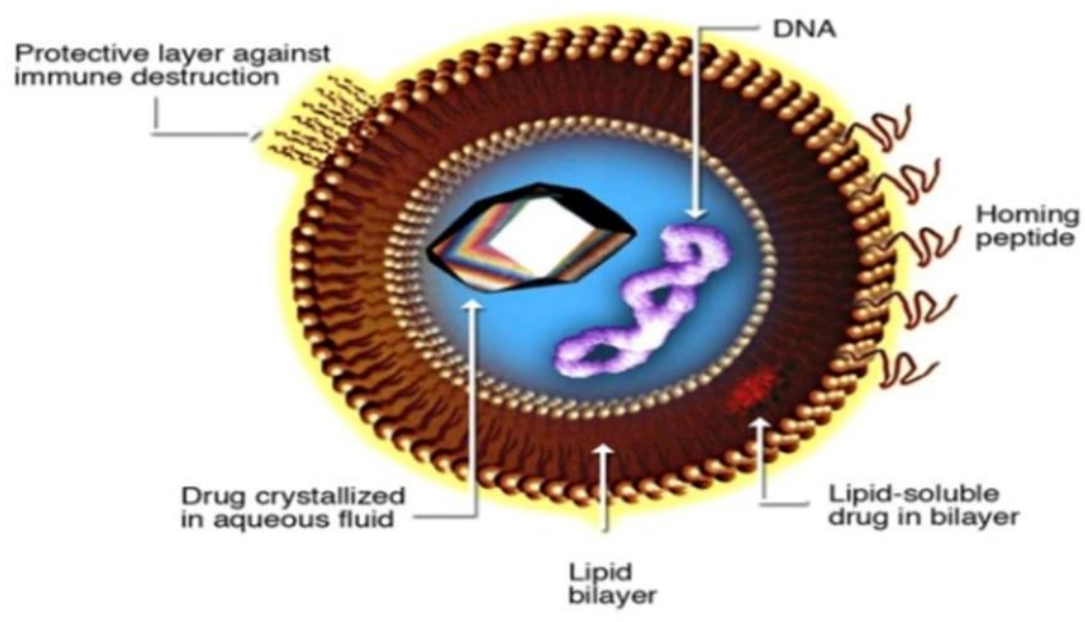

Figure 4 Liposome for drug delivery. [21]

\subsection{Gene therapy technologies}

The transfer of genetic material can be accomplished in vivo through local or systemic inoculation or ex vivo where the target of interest is collected and modified outside of the organism before return to the host. Transfer of synthetic DNA can be accomplished by transduction or transfection. Such methods of transfer include either direct injection of DNA into the recipient cells, or utilising methods to induce membranes permeation, receptor mediated uptake or endocytosis. Transduction utilises recombinant virus as a vector for gene transfer. Entry of these vectors is mediated by cell-surface receptors. Concerns regarding the immunogenicity of viral vector systems due to activation of memory responses against constituent viral proteins or a primary response to neoantigens has spawned the evolution of synthetic gene delivery systems which exploit transfection, the transfer of DNA via physical, chemical or electrical methods.[22,23] Benefits of non-viral methods for DNA transfer include a reduction of risks associated with viruses (immune response, insertional mutagenesis) and limitations to gene delivery (such as length of the transgene cassette).[24]

\subsubsection{IFN- $\beta$}

Human IFN- $\beta$ is thought to be an important factor in the growth of human glioma and melanoma because homozygous deletions of the class I IFN gene cluster, comprising multiple IFN- $\alpha$ genes and a single IFN- $\beta$ gene, have been demonstrated in these tumors. $[25,26]$ In the 1980 s, IFN- $\beta$ protein was clinically used as an anticancer drug in Japan, and it showed a clear growth-inhibitory effect on malignant glioma and melanoma. [27, 28] However, tumor regression was observed in only $10-30 \%$ and $15-20 \%$ of the patients treated for glioma and melanoma, respectively, and survival prolongation was not attained in either. [29] IFN- $\beta$ protein also deserves attention as a cell-cycle regulator, including aberrant cell-cycle progression, which occurs predominantly as S phase accumulation, and less frequently as other cellcycle effects, such as GI arrest, or the entry of tumor cell into a senescent-like state. [30] 


\subsubsection{Antitumor mechanism of IFN- $\beta$ gene transfer}

We investigated the antitumor activity of IBN- $\beta$ gene therapy in both in vitro and in vivo experiments. In the in vivo experiments, human glioma cells were implanted into the brain of nude mice. One week after implantation, the tumor cells formed a mass $2 \mathrm{~mm}$ in diameter. From this time point, we started injection of liposomes containing human IFN- $\beta$ gene 6 times every other day. One month later, the tumor was eradicated completely, although repeated direct injections of human IFN- $\beta$ protein (100 IU) did not suppress the tumor growth at all. We therefore analysed in detail the mechanism of this surprising antitumor effect induced by IFN- $\beta$ gene transfer. From our previous experiments, we speculated that the IFN- $\beta$ gene has four antitumor effects on glioma cells (fig. 5) Interestingly, IFN- $\beta$ gene transfer by means cationic liposomes induces apoptosis of cultured human glioma cells that are resistant to IFN- $\beta$ protein. Summarizes the molecular mechanisms of apoptosis induced by IFN- $\beta$ gene transfer via cationic liposomes. Susceptibility to extrinsically supplied IFN- $\beta$ protein correlated closly with the amount of intracellular IFN- $\beta$ mRNA in cultured human glioma cells, in agreement with the findings of Hanson et al. in melanoma cell lines. [31]

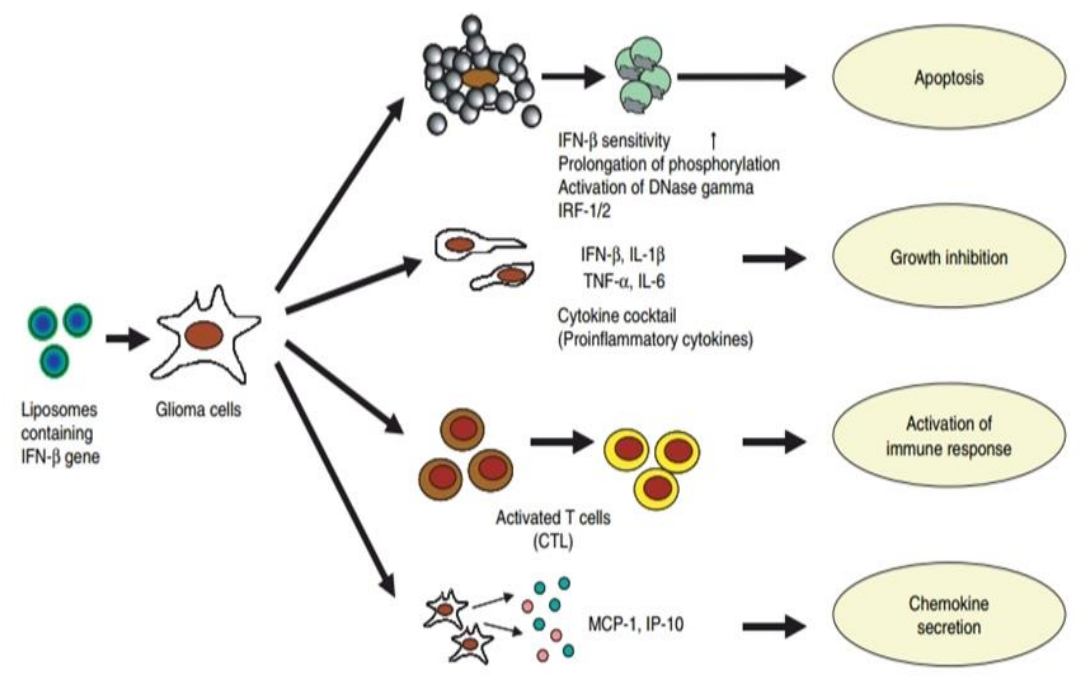

Figure 5 Summary of antitumor mechanisms of IFN- $\beta$ gene therapy for malignant glioma. There are at least four antitumor mechanisms of IFN- $\beta$ gene therapy for malignant glioma; induction of apoptosis. IFN- $\beta$ gene transfer by means of cationic liposomes can induce apoptosis in IFN- $\beta$ protein-resistant cells; IFN- $\beta$ gene transfer to glioma cells produces some cytokines such as interleukin (IL)-1 $\beta$, IL- 6 , and tumor necrosis factor (TNF)- $\alpha$ in addition to IFN- $\beta$. The mixture of these cytokines exerted a strong antitumor effect on glioma cells; IFM- $\beta$ gene transfer activates systemic immune response and facilitated immune cell infiltration into a brain tumor, although the brain is an immunologically privileged site.

\section{Physical Methods to Enhance Delivery}

\subsection{Electroporation}

Electroporation is a method that uses short pulses of high voltage to carry DNA across the cell membrane. This shock is thought to cause temporary formation of pores in the cell membrane, allowing DNA molecules to pass through. Electroporation is generally efficient and works across a broad range of cell types. However, a high rate of cell death following electroporation has limited its use, including clinical applications. Some of the drawbacks of electroporation can be overcome by using of high-voltage plasma discharge DNA was efficiently delivered following very short pulse. [32] 

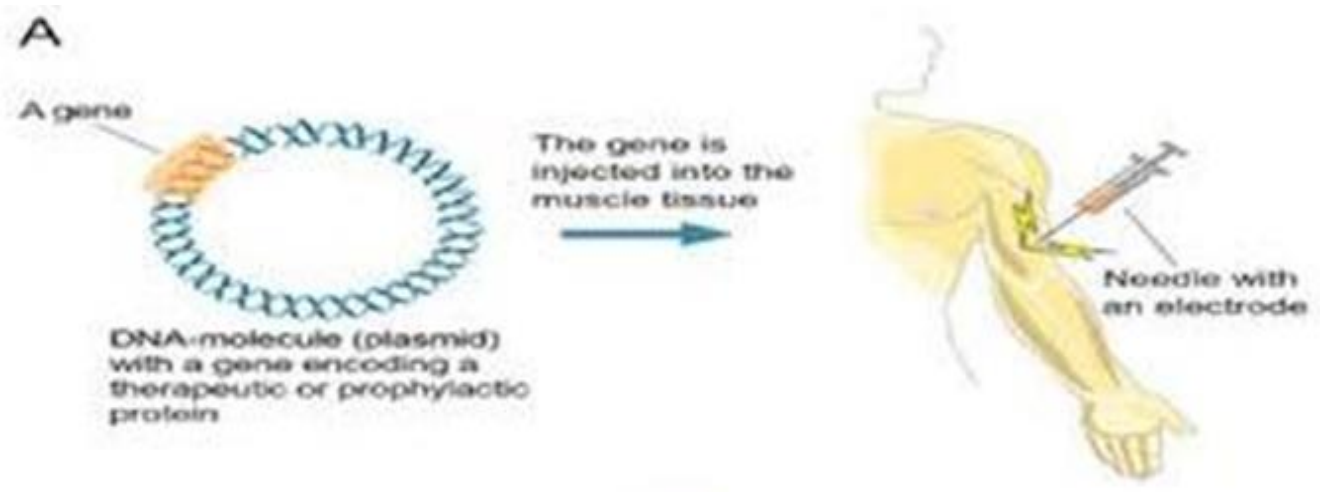

B

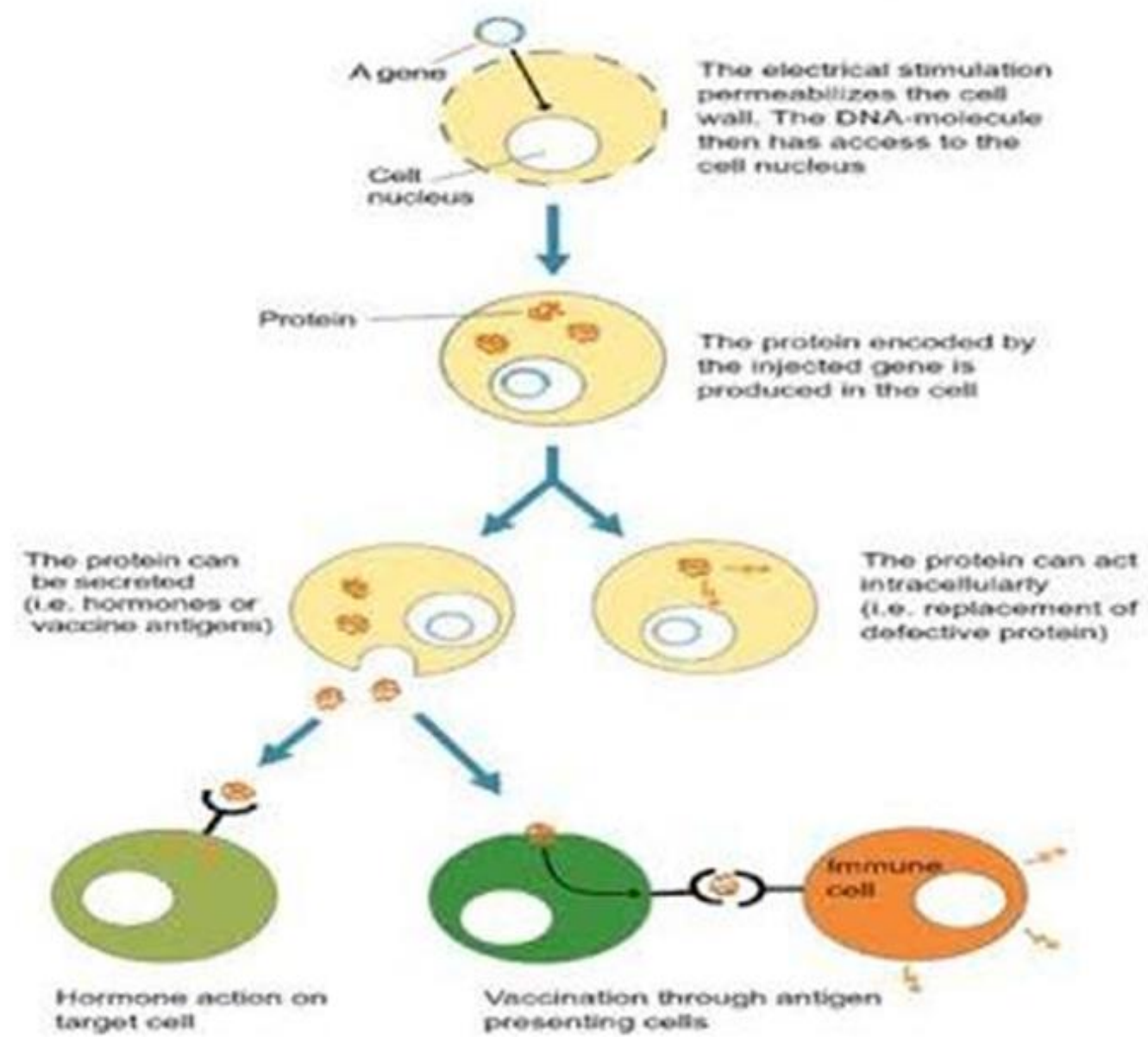

Figure 6 Diagram of the method of gene therapy using electroporation

\subsection{Gene gun}

The use of particle bombardment, or the gene gun, is another physical method of DNA transfection. In this technique, DNA is coated with gold particles and loaded into a device which generates a force to achieve penetration of DNA/gold into the cells. Eg:- If the DNA is integrated in the wrong place in the genome, for example in a tumour suppressor gene, it could induce a tumour. This has occurred in clinical trials for X-linked severe combined immunodeficiency (X-SCID) patients, in which hematopoietic stem cells were transduced with a corrective transgene using a retrovirus, and this led to the development of T cell leukaemia in 3 of 20 patients. [33] 


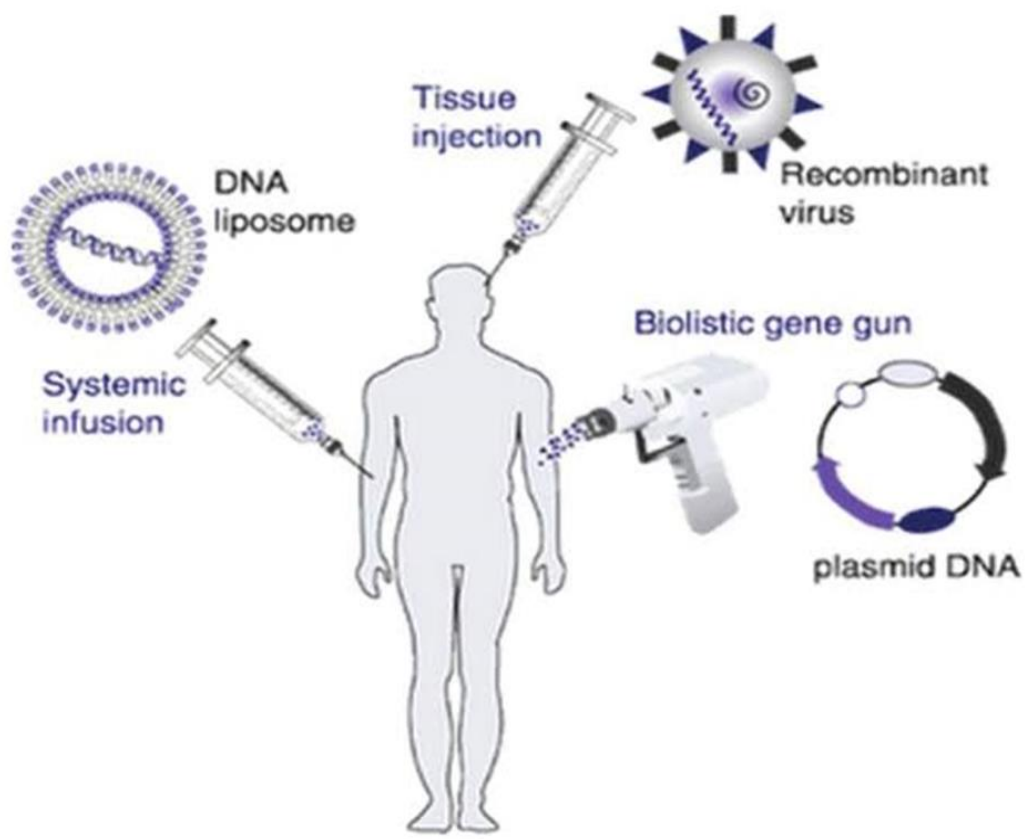

Figure 7 Gene gun method

\subsection{Sanoporation}

Sonoporation uses ultrasonic frequencies to deliver DNA into cells. The process of acoustic cavitation is thought to disrupt the cell membrane and allow DNA to move into cells. The ultrasound produces microscopic cavitation bubbles in the mixture of cells. These cavitation bubbles can then implode producing a shockwave while on or near the surface of a cell membrane the tiny shockwave produce pores in the cell membrane allowing for DNA/RNA to diffuse into the cell. [34]

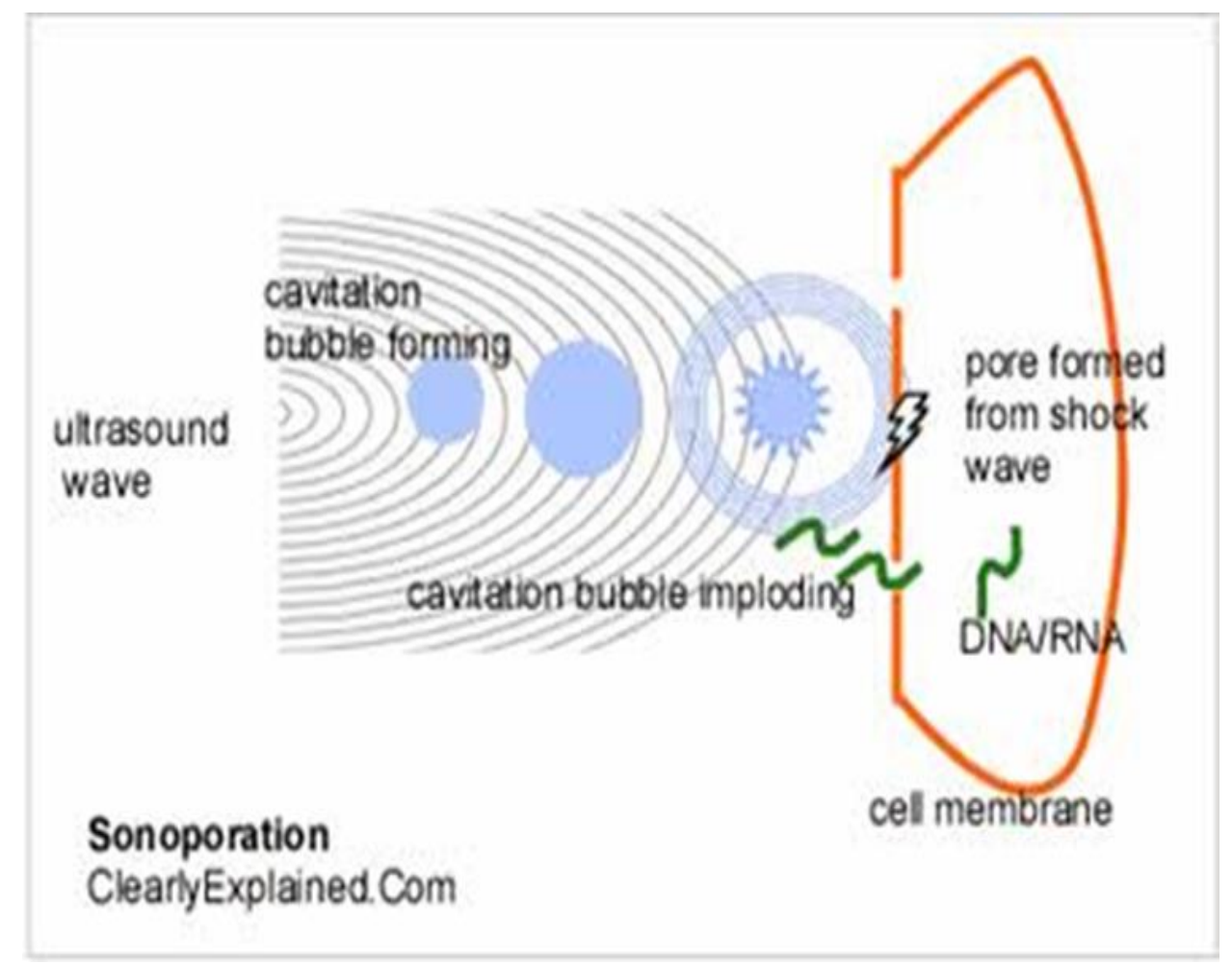

Figure 8 Sanoporation 


\subsection{Magnetofection}

In a method termed magnetofection, DNA is complexed to a magnetic particles and a magnet is placed underneath the tissue culture dish to bring DNA complexes into contact with a cell monolayer.
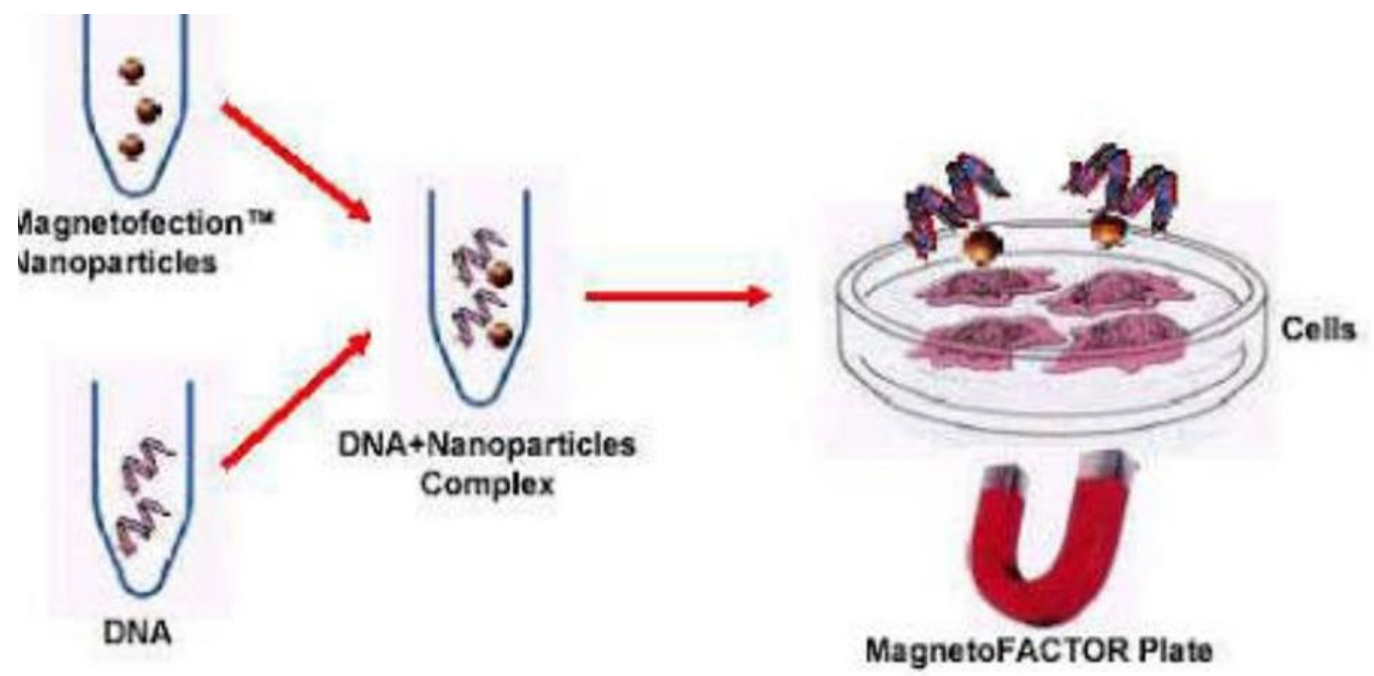

Figure 9 Method of magnetofecion

\section{Chemical Method to Enhance Delivery}

\subsection{Oligonucleotides}

The use of synthetic oligonucleotides in gene therapy is to inactivate the genes involved in the disease process. There are several methods by which this is achieved. One strategy uses antisense specific to the target gene to disrupt the transcription of the faulty gene. Another uses small molecules of RNA called siRNA to signal the cell to cleave specific unique sequences in the mRNA transcript of the faulty gene, disrupting translation of the faulty mRNA and therefore expression of the gene. [35]

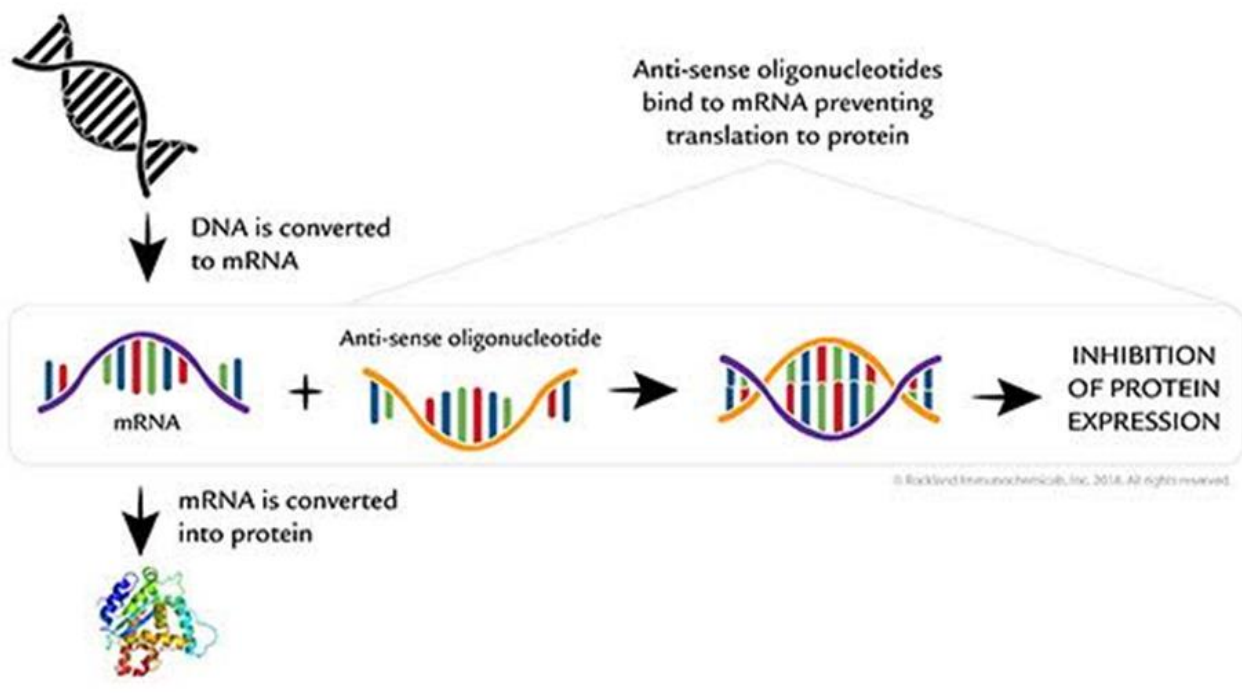

Figure 10 Antisense oligonucleotide mechanism 
Our anti-sense oligonucleotides antibodies developed are useful to support characterization studies of ASO also known as anti-sense drug. ASO antibodies exhibit sequence or modification specific binding properties and are intended for application including ELISA.

\subsection{Lipoplexes and polyplexes}

To improve the delivery of the new DNA into the cell, the DNA must be protected from damage and (positively charged). Initially, anionic and neutral lipids were used for the construction of lipoplexes for synthetic vector.

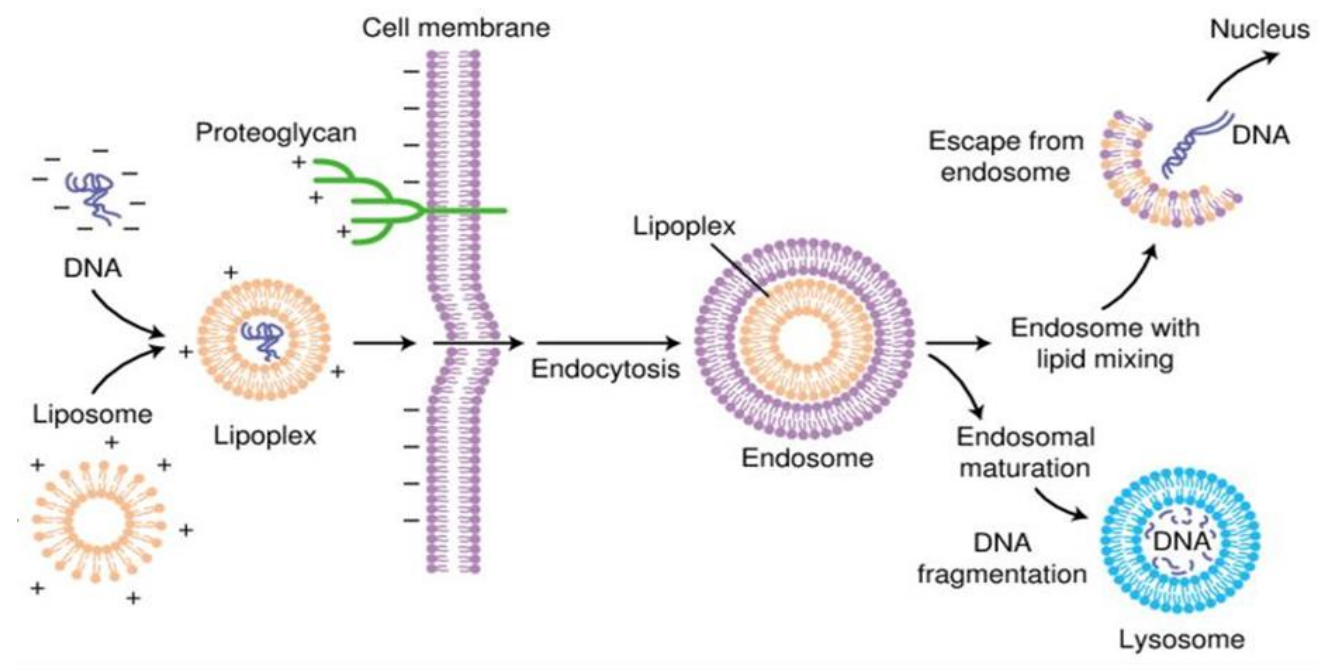

Figure 11 Lipoplex-mediated transfection and endocytosis

Lipoplex-mediated transfection and endocytosis, cationic lipids forming micellar structure called liposomes are complexed with DNA to create lipoplexes. The structure fuse with the cell membrane, at least sometimes after interactions with surface proteoglycans. [36]

\subsection{Dendrimers}

A dendrimer is a highly branched macromolecule with a spherical shape. The surface of the particle may be functionalized in many ways and many of the properties of the resulting construct are determined by its surface. In particular it is possible to construct a cationic dendrimer, i.e. one with a positive surface charge. When in the presence of genetic material such as DNA or RNA, charge complimentarily leads to a temporary association of the nucleic acid with the cationic dendrimer. On reaching its destination the dendrimer-nucleic acid complex is then taken into the cell via endocytosis. [37]

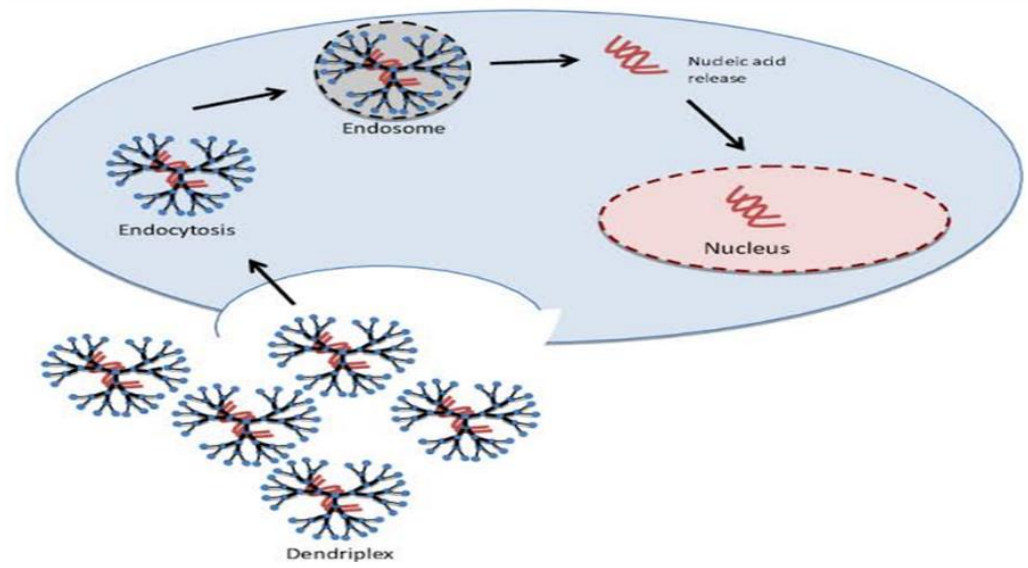

Figure 12 Dendrimers 


\subsection{Hybrid methods}

Due to every method of gene transfer having shortcomings, there have been some hybrid methods developed that combine two or more techniques. [38] Virosomes are one example; they combine liposomes with an inactivated HIV or influenza virus. This has been shown to have more efficient gene transfer in respiratory epithelial cells than either viral or liposomal methods alone. Other methods involve mixing other viral vectors with cationic lipids or hybridising viruses. [39]

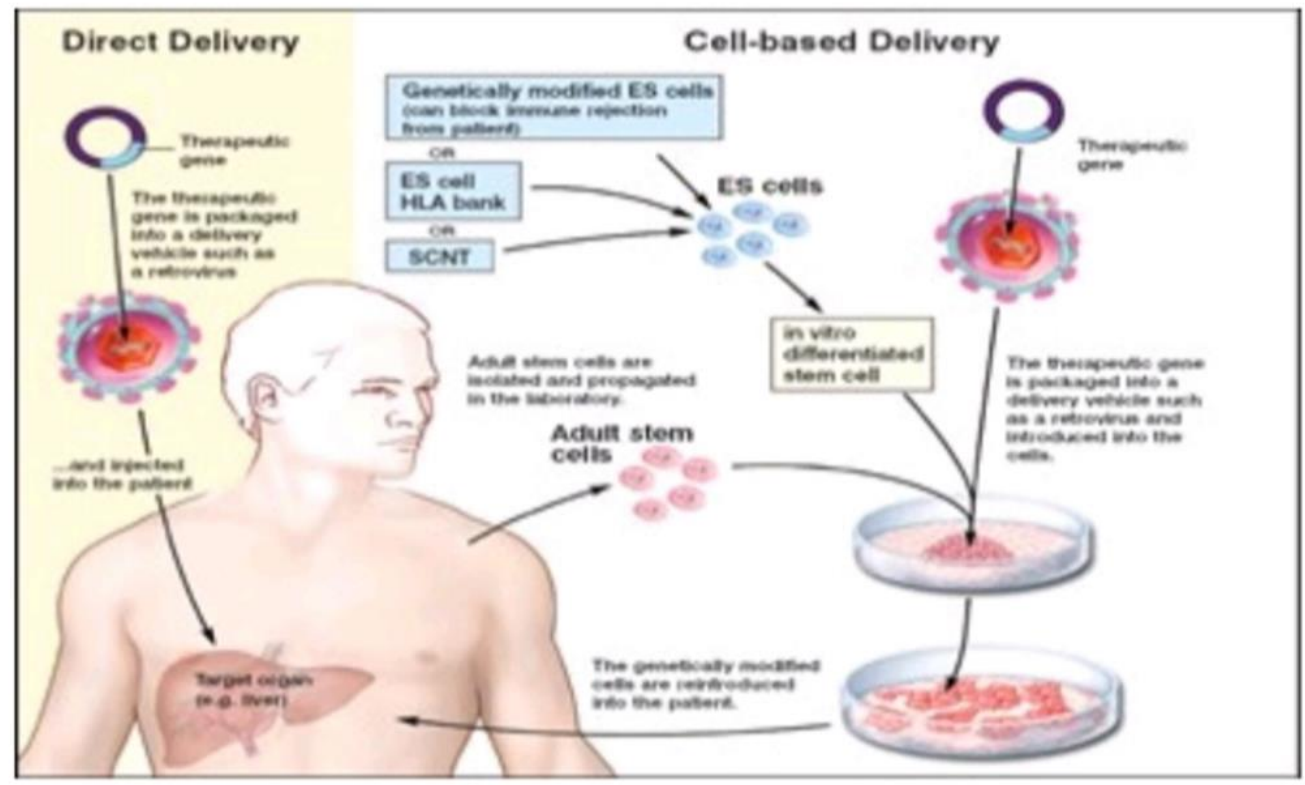

Figure 13 Delivery of gene by direct and cell based methods

\section{Advantages of gene therapy}

- In case of 'silence' a gene. In the case of someone with HIV, which had not yet developed into AIDS, scientists could save them the pain and suffering of the disease by using gene therapy to 'silence' the disease before its onset.

- Gene therapy has the potential to eliminate and prevent hereditary diseases such as cystic fibrosis and is a possible cure for heart disease, AIDS and cancer.

- These sceptics would almost certainly choose gene therapy, especially if it was the last hope for them or one of their loved ones - as is the case for many gene therapy patients. [40]

\section{Disadvantages of gene therapy}

- $\quad$ Short-lived nature of gene therapy.

- Immune response - Genes injected with a virus may trigger an immune response against the virus. Problems with viral vectors (once inside the patient, the viral vector could recover its ability to cause disease).

- Multigene disorders - The genetic material might not get into the right cell, or the right place in the cell's DNA. [41]

\section{Conclusion}

Most scientists believe the potential for gene therapy is the most exciting application of DNA science, yet undertaken. How widely this therapy will be applied, depends on the simplification of procedure. As gene therapy is uprising in the field of medicine, scientists believe that after 20 years, this will be the last cure of every genetic disease. Genes may ultimately be used as medicine and given as simple intravenous injection of gene transfer vehicle that will seek our target cells for stable, site-specific chromosomal integration and subsequent gene expression. And now that a draft of the human genome map is complete, research is focusing on the function of each gene and the role of the faulty gene play in disease. Gene therapy will ultimately change our lives forever. 


\section{Compliance with ethical standards}

\section{Acknowledgments}

With reverence, I sincerely accentuate my everlasting heartfelt gratitude and indebtness to my guide Archana D. Kajale, Madhuri A. Channawar and Shilpa R. Gawande. I own special thanks to my friends for their valuable suggestions and help.

\section{Disclosure of conflict of interest}

We declare that we have no conflict of interest.

\section{References}

[1] Culver K. Gene Therapy-A Handbook for Physicians. Mary Ann Liebert, Inc, New York. 1994; 78-86.

[2] Cavazzana-Calvo M, Hacein-Bey S, de Saint Basile G, Gross F, Yvon E, Nusbaum P, Selz F, Hue C, Certain S, Casanova JL, Bousso P, Deist FL, Fischer A. Gene therapy of human severe combined immunodeficiency (SCID)-X1 disease. 2000; 288: 669-72.

[3] Cavazzana-Calvo M, Fischer A. Gene therapy for severe combined munodeficiency: are we there yet? J Clin Invest. 2007; 117: 1456-65.

[4] Aderson WF. Human gene therapy, Nature. 1998; 392(Suppl 6679): 25-30.

[5] Mulherkar R. Gene therapy for cancer, Curr Sci. 2001; 81:555-60.

[6] Nichols Eve K. Human Gene Therapy, Cambridge, MA: Harvard University Press. 1988.

[7] Moolten FL, Vonderhaar BK, Mroz PJ. Transduction of the herpes thymidine kinase gene into premalignant murine mammary epithelial cells renders subsequent breast cancers responsive to ganci.

[8] Agard C, Ligeza C, Dupas B, et al. Immune-dependent distant bystander effect after adenovirus-mediated suicide gene transfer in a rat model of liver colorectal metastasis. Cancer Gene Ther. 2001; 8: 128-36.

[9] Disis ML, Bernhard H, Jaffee EM. Use of tumour-responsive T cells as cancer treatment. Lancet. 2009; 373: 67383.

[10] Rosenberg SA, Aebersold P, Cornetta K, Kasid A, Morgan RA, Moen R, Karson EM, Lotze MT, Yang J C,Topalian S L. Gene transfer into humans-immunotherapy of patients with advanced melanoma, using tumor-infiltrating lymphocytes modified by retroviral gene transduction. N Engl J Med. 1990; 323: 570-78.

[11] Durai S, Mani M, Kandavelou K, Wu J, Porteus MH, Chandrasegaran S. Nucleic Acids Res. 2009; 33: 5978-90.

[12] Nabel EG, Nabel GJ. Direct gene transfer: basic studies and human therapies. Thromb Haemost. 1993; 70: 202203.

[13] Harwood, Adrian J, Protocol for Gene Analysis.

[14] Fridmann T, Roblin R, Science. 1972; 175(25): 949.

[15] Gardlik R, Palffy R, Hodosy J, Lukacs J, Turna J, Celec P. Vectors and delivery systems in gene therapy. Med. Sci. Monit. 2005; 11(4): 110-121.

[16] Par TG, Jeong JH, Kim SW. Current status of polymeric gene delivery systems. Adv Drug Del Rev. 2006; 58: 467486.

[17] Yoshino H, Hashizume K, Kobayashi E. Naked plasmid DNA transfer to the porcine liver using rapid injection with large volume. Gene Ther. 2006; 13: 1696-1702.

[18] Yazawa H, Murakami T, Li HM, Back T, Kurosaka K, Suzuki Y. Hydrodynamics based gene delivery of naked DNA encoding fetal liver kinase-1 gene effectively suppresses the growth of pre-existing tumors. Cancer Gene Ther. 2006; 13: 993-1001.

[19] Cemazar M, Golzio M, Sersa G, Rols MP Teissie J. Electrically-assisted nucleic acids delivery to tissues in vivo: where do we stand? Curr Pharm Des. 2006; 12: 3817-3825.

[20] Wolff JA Budker V. The mechanism of naked DNA uptake and expression. Adv Genet. 2005; 54: 3-20. 
[21] Alvarez-Erviti L, Seow Y, Yin HF et al. Delivery of siRNA to the mouse brain by systemic injection of targeted exosomes. 2011.

[22] Aihara H Miyazaki J. Gene transfer into muscle by electroporation in vivo. Nat Biotechnol. 1998; 16: 867-870.

[23] Mann MJ, Gibbons GH, Hutchinson H, Poston RS, Hoyt EG. Pressure-mediated oligonucleotide transfection of rat and human cardiovascular tissues. Proc Natl Acad Sci U SA. 1999; 96: 6411-6416.

[24] Andre F, Mir LM. DNA electrotransfer: its principles and an updated review of its therapeutic applications. Gene Ther. 2004; 11: S33-42.

[25] Miyakoshi J, Dobler KD, Allalunis-Turner J, McKean JDS, Petruk K, Allen PBR, Aronyk KN, Weir B, HuyserWierenga D, Fulton D, Urtasun RC, Day RS III. Absence of IFNA and IFNB genes from human malignant glioma cell lines and lack of correlation with cellular sensitivity to interferons. Cancer Res. 1990; 50: 278-83.

[26] James CD, Carlbom JHE, Nordenskjold M, Cavenee WK, Collins VP. Chromosome 9 deletion mapping reveals interferon $\beta$ and interferon $\beta$-1 gene deletion in human glial tumors. Cancer Res. 1991; 51: 1684-8.

[27] Larsson I, Landstrom LE, Larner E, Lundgren E, MiornerH, StrannegardO. Interferon production in glia and glioma cell lines. Infect Immune. 1978; 22: 786-9.

[28] Nehashi K, Yoshida J, Wakabayashi T, Nagata M, Utsumi J, Naruse N, Sugita K. Growth inhibition of human glioma cells by superiduced human interferon- $\beta$. Neurol Med Chir (Tokyo). 1995; 35: 719-22.

[29] Salazar AM, Levy HB, Ondra S, Kende M, Scherokman B, Brown D, Mena H, Martin N, Schwab K, Donovan D, Dougherty D, Pulliam M, Ippolito M, Graves M, Brown H, Ommaya A. Long term treatment of malignant gliomas with intramuscularly administered polyinosinic-polycytidylic acid stabilized with polylysine and carboxymethylcellulose; an open pilot study. Neurosurgery. 1996; 38: 1096-104.

[30] Kaynor C, Xin M, Wakefield J, Barsoum J, Qin XQ. Direct evidence that IFN-beta functions as a tumor-suppression protein. J Interferon Cytokine Res. 2002; 22: 1089-98.

[31] Hanson C, Koepf I, Weijdegard A, Sterner U, Sensitivity to extrinsically supplied interferon and the endogenous expression of interferon in melanoma cell lines. Melanoma Res. 19999; 451-6.

[32] Dubay RC. A textbook of biotechnology $1^{\text {st }}$ edition, S. Chand and company, New Delhi. 2004.

[33] Gupta PK. Elements of biotechnolog $1^{\text {st }}$ edition, Rastogi Publication, Meerut.2001.

[34] Sataynarayan U, biotechnology $1^{\text {st }}$ edition, Book and allied (p) Ltd, Kolkata.

[35] Gene delivery by lipoplexex nad polyplexex by Conchita Tros de llarduyaand et all.

[36] Nonviral gene delivery: Techniques and implications for molecular medicines by Alan L. Parker and et all.

[37] Understanding gene therapy (Book) by N. R. Lemoine.

[38] Woods NB, Bottero V, Schmidt M, von Kalle C, Verma IM. Gene therapy: therapeutic gene causing lymphoma. Nature. 2006; 440: 7088.

[39] Wang Hongj W, Dmitry M, Leege T, Harkey M, Li Q, Thalia P, George S, Lieber A. A Capsid-Modified HelperDependent Adenovirus Vector Containing the $\beta$-Globin Locus Control Region Displays a Non-random Integration Pattern and Allows Stable, Erythroid-Specific Gene Expression Journal of Virology. 2005; 79(17): 10999-101.

[40] Horn PA, Morris JC, Neff T, Kiem H.P, Mol. Ther.2004; 10(3): 417-31.

[41] Jenkins R, Meng QH, Hodges RJ, Lee LK, Bottoms SEW, Laurent GJ, Willis D, Ayazi Shamlou P, McAnulty RJ, Hart SL, Farhood H, Serbina N,Huang L. Biochim. Biophys. Acta. 1995; 1235: 289-295. 